\title{
7. Conclusions
}

In this study I have outlined the predominant interpretation of the international human right to health, and explored what it would mean to interpret this right by adopting the principle of solidarity.

In chapter two, I began by showing that the predominant interpretation of the right to health conceives this human right as an individual legal right: a subjective entitlement, justiciable in court, which to a large extent is informed by the notion of vulnerability. This perspective is reflected in the minimum core of rights doctrine, the prohibition of discrimination and a special focus on disadvantaged people such as minority groups.

The main problem with conceiving the right to health as a legal right is that it gets in the way of being able to deploy appropriate mechanisms to address the structural nature of the problems that social rights were 'raised' to combat. Social rights emerged as an answer to a number of social malaises, including poverty and social inequality and other forms of deprivation and marginalization. Conceived as a legal right, the right to health connects with the needs of the isolated individual but fails to tackle the intrinsically collective elements of social rights: their democratic pedigree, the principles of distributive justice that these rights uphold, the trade-offs reflecting the background to these rights and the collective nature of the remedies that best address their social nature. As an expression of these limitations, I concluded the second chapter by noting the intrinsic difficulty in reconciling equality of opportunity with the highest standard of health; a denomination that goes beyond formal equality and which is linked to solidarity.

The predominant interpretation understands the asymmetries between so-called first generation and second generation rights in connection with the lack of justiciability of the latter. However, when developing the principle of solidarity in chapter three, I noted that for Post-War liberals the equal universalization of social rights did not require the judicialization of access-related issues. This is not to say that judicial remedies have no role to play, for example in addressing discrimination. Yet, it would be wrong to identify the asymmetry between both sets of rights as an issue of discrimination or court justiciability. The real asymmetry lies in the limited extent to which the duties protecting social rights have been structured in the public domain compared to those of civil and political rights. If, at best, the right to health entails a State subsidy to cover the expenses of the healthcare industry when they tackle 
the ones that for them are financially unattractive, the extent that access to healthcare is a public good is humbler in comparison to civil and political rights. Noting how the right to vote generates equality of outcome by means of the one-person one-vote principle, I concluded that if the goal is to treat both sets of rights equally, as envisaged at the Human Rights World Conference in Vienna in 1993, State action must go further than merely subsidizing the private sector.

Another issue with the predominant interpretation is the lack of attention in relation to the rules regulating the access, financing and provision of healthcare, as well as the institutions in charge of carrying out that enterprise. The result is that under the predominant interpretation of the right to health: (a) the provision of healthcare services can be either public, private or mixed; (b) no State institution is under a duty to deliver healthcare services per se; (c) commercialization is not opposed to human rights per se; and (d) healthcare services do not necessarily have to be free of charge.

On the other hand, the predominant interpretation does promote the prohibition of discrimination, an affordable provision of healthcare services and the regulation of these services. Non-discrimination has done a great deal for human rights, but it cannot possibly be expected to structurally shift the market so that everyone gets the same. Asking non-discrimination to correct the market fails to appreciate that the principles of distribution, according to which the market operates, are not accountable from the point of view of distributive justice. Rather, irrespective of the practical reality, market principles describe an interaction which is regarded as commutative, and where all individuals relate to one another via relationships of supply and demand. Under those principles, it is not 'unjust' to give something in exchange for anything less than its market price. Given that not everybody has the same purchasing power, it is not conducive to expect market principles to allow everyone to attain the same services.

Admittedly, standard human rights law expressions such as affordability of basic services or regulation may curb the intrinsically unequal distribution logic of market principles, generating limited public goods. However, it is also true that positioning those tools at the core of authoritative human rights law interpretations has had the effect of legitimizing the market delivery of healthcare services. The market not only becomes the default way to provide healthcare services, but it has also become the very indicator to determine human rights involvement. In doing so, far from halting unequal distribution logic, human rights are legitimizing the most formidable source of health inequities.

To constantly revolve around the protected (vulnerable) legal subjects only partially realizes the duty of the right to health. The vulnerable may get a minimum, but from the moment that the market provision of healthcare services becomes acceptable to human rights, a parallelism emerges: the divide 
between the institutions that serve those who can purchase these services in the market vis-à-vis the institutions that serve those who cannot. In such a divide, the political priority attached to those who are served by the latter institutions pales in comparison to the political priority afforded to those who are served by the former. Moreover, as the right to health was already regarded as being compatible with the market, the predominant interpretation can do little to counter this trend. Of little relevance is the fact that the ECOSOC Committee observes with concern, in some Concluding Observations, the existence of a divide in the extension and quality of the commercial provision of healthcare services vis-à-vis their public counterpart. While the Committee outlines the entirely foreseeable disparities of access generated by healthcare commercialization, going as far as opposing that phenomenon is never presented as a task the right to health would be able to mandate. These perspectives, well embedded in a set of frameworks defining what human rights are supposed to be about, make it hard for the right to health to reconnect with its social justice roots. The motto of 'Health for All' of the Alma-Ata Declaration, as raised once by the WHO, and still supported by grassroots international health movements such as the People's Health Movement, is not the focus of the predominant interpretation.

Without further characterization of the right to health's duties, without identifying the inherent characteristics of social rights such as the right to health, and without attempting to explicitly tackle the menaces that social rights were born to eradicate, the prospects of the right to health are not bright.

In light of this prospect, it is time to return to the questions that motivated this book - can solidarity provide an alternative interpretation of this human right and if so, how does solidarity give weight to the right to health?

Chapter three explored the substance of solidarity and the relationships connecting this principle to health issues. Examining various legal instruments within international human rights law, it appears that many links exist between the history of social rights and the principle of solidarity. Solidarity's most important contribution is to inform the principles of distributive justice that apply to social rights. Solidarity promotes principles of distribution that are able to ensure universal access to social rights. In this respect, the principle of distribution preferred by solidarity is citizenship, as opposed to the unequal logic of market principles which distribute goods and services in accordance with ability to pay.

As discussed in the second half of chapter four, this input from solidarity manifests itself at the level of the positive obligations of the right to health, rendering it a collective right. Under solidarity, these positive obligations give shape not to a legal right, but to a non-marketed right. This is achieved by an obligation to protect and an obligation to fulfil. The obligation to protect primarily discourages and ultimately prohibits the marketed provision of 
healthcare services. In turn, the obligation to fulfil, through decommodification, ensures the provision of healthcare services free of charge. Moreover, in the judicial sphere, solidarity provides insights into the Covenant's notion of the progressive realization of social rights. As suggested when looking at an important case from Portugal's Constitutional Court, this could consist in the judiciary's ability to retract the commodification of access to healthcare. The interplay of these various aspects allow for ensuring the legal protection of a much more comprehensive public good; one where access to healthcare does not only depend on the position of vulnerability of specific individuals, but on the idea that access to healthcare should be distributed on the basis of need.

I argued that under solidarity citizenship should not be regarded as the only principle of distribution guiding the provision of healthcare services; solidarity can also relate to the idea of medical need. This idea is consistent with the ICESCR, which in Article 12(2)(d) considers medical need to be a principle of distribution for the right to health. Yet, when read in combination with the prohibition of discrimination on national grounds as established by Article 2(2) of the same treaty, this idea reflects the most ambitious emancipatory horizons of the Bill of Human Rights, which according to Article 28 of the Universal Declaration of Human Rights, should be understood along the lines of the right to an equitable international order. In this understanding, solidarity appears as the natural principle steering the construction of a cosmopolitan project of citizenship, where the legal scope of the right to health is not limited by territorial considerations. Consequently, regarding non-nationals within the State's jurisdiction, the State should realize the right to health without discrimination. I also argued that regarding the right to health of persons located beyond the State's borders, respect for the right to self-determination should lead to its realization through international cooperation.

A further point of contact between solidarity and inherent elements of social rights concerned trade-offs. I have shown that the point is not to deny the trade-offs inherent to the ineradicable scarcity of economic resources, but to take issue with trade-offs opposed to citizenship and medical need as principles of distribution. Furthermore, solidarity also provides insights when it comes to the collective remedies better fitting the multiple needs in the context of scarce resources that describe social rights. What solidarity can add in this respect are the positive obligations of the right to health which, breaking with the unequal logic of market distribution principles, requires understanding that the State discharges its obligations by instituting a national healthcare system that is free and accessible to all persons situated under the State's jurisdiction.

Important overlaps can be detected between health-financing systems that rely on the market and the predominant interpretation of the right to health. The individualistic perspective of the right to health, so prone to protect the 'deserving poor', fits well with systems that are mainly built around market 
principles and where the action of the State subsidizes those unable to purchase social rights in a market context. This contrasts with Cuba's tax-funded healthcare system. Under solidarity, the unavoidable trade-offs are not carried out sacrificing the weakest, but in accordance with principles of distributive justice and sound public health evidence. Furthermore, the equality and universal focus of Cuba's healthcare system not only entail the basic presuppositions for a human rights-based discussion of efficiency. The impressive achievements that Cuba's healthcare system has reached with its limited resources, show that justice is not necessarily opposed to economic efficiency.

States that have signed the Covenant are free to interpret the legal obligations derived from this treaty in a way that is not necessarily in line with the predominant interpretation of the right to health. Despite the authority and widespread recognition enjoyed by the bodies that defend that understanding, I conclude that the predominant interpretation of the right to health has several flaws that require careful assessment. The inability of the authoritative bodies to identify the commercialization of healthcare as the greatest threat to this human right is a fundamental part of the problem. Furthermore, the main asymmetry between social rights such as the right to health and classical civil and political rights, does not stem from the lack of justiciability of the right to health in court, but from thinking that is out of the competence of social rights to put aside the market, property, entrepreneurialism and search for profits, which threatens the goal of equal access to healthcare for all. This asymmetry is what continues to assign economic, social and cultural rights a lower status. The commercialization in healthcare which defines the present era, is also illustrative of the crossroads where the human rights project currently stands. Time will tell whether the human rights project is in fact as fundamental as its most conspicuous advocates constantly proclaim it to be. Either it will triumph by overmastering our political economy or, submissive to market imperatives, it will become less relevant as a narrative of emancipation. 